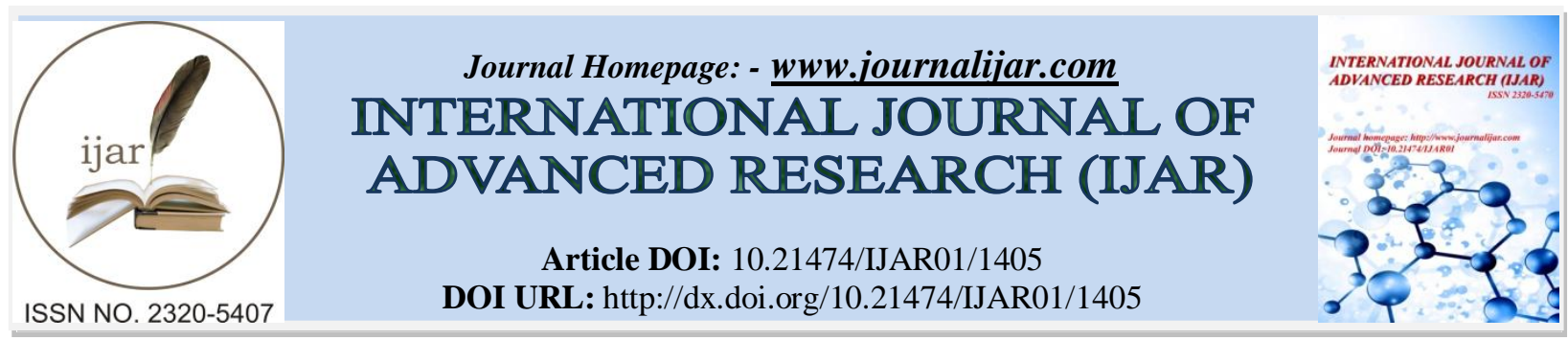

RESEARCH ARTICLE

\title{
ULTRASONIC STUDIES ON BINARY LIQUID MIXTURES OF METHYL ACRYLATE WITH 2- ALKOXY ETHANOLS AT 308.15 K.
}

\author{
Dr. K. Vijaya Lakshmi \\ Lecturer in Chemistry, Govt. Degree College (UG \& PG) (Autonomous), Anantapur, A.P., India.
}

\section{Manuscript Info}

Manuscript History

Received: 12 June 2016

Final Accepted: 19 July 2016

Published: August 2016

Key words:-

Ultrasonic velocity, Methyl acrylate, 2Alkoxy Ethanols, Excess isentropic com pressibility, Excess acoustic impedance and Redlich Kister equation.

\begin{abstract}
Densities and ultrasonic velocities of binary liquid mixtures of Methyl Acrylate with 2-Alkoxy Ethanols [2-Methoxy Ethanol, 2-Ethoxy Ethanol, 2-Butoxy Ethanol] have been measured at $308.15 \mathrm{~K}$. The observed data have been utilised to calculate various acoustical parameters like Isentropic compressibility, Intermolecular free length, Acoustic impedance and Relative association. The various excess properties like Excess ultrasonic velocity, Excess acoustic impedance, Excess isentropic compressibility and Excess Inter molecular freelength were calculated and fitted to the Redlich Kister equation.
\end{abstract}

\section{Introduction:-}

In recent years, density and ultrasonic velocity measurements in pure liquids and liquid mixtures have been successfully employed in understanding the nature of intermolecular interactions. Physico chemical and thermodynamic investigations play an important role to understand the nature and extent of the aggregation of molecules that exists in the binary liquid mixtures and their sensitivities to the variations in composition and the molecular structure of the pure components [1-2].

The ultrasonic velocity measurement is an excellent tool to investigate inter and intermolecular interactions between liquid mixtures of non-electrolytes. Density and ultrasonic velocity properties of binary liquid mixtures are essential in process simulation, equipment design, solution theory, important parameter in calculations of the thermodynamic properties of matter and molecular dynamics. Acoustic properties are useful in understanding the molecular interactions. The propagation of sound in real liquids is accompanied by irreversible loss of energy resulting in the absorption of sound by medium. The irreversibility of the process of propagation of sound waves in a liquid is associated primarily with its viscosity and thermal conductivity.

The present research aims to measure densities and ultrasonic velocity of binary liquid mixtures of methyl acrylate (MA) with 2-Alkoxy Ethanols [2-Methoxy Ethanol (2ME), 2-Ethoxy Ethanol (2EE), 2-Butoxy Ethanol (2BE)] at $308.15 \mathrm{~K}$, by using this data various acoustical parameters like Acoustic impedance ( $Z$ ), Isentropic compressibility $\left(K_{s}\right)$, Inter molecular free-length $\left(L_{f}\right)$ and Relative association $\left(\mathrm{R}_{\mathrm{A}}\right)$ and also various excess properties like excess ultrasonic velocity $\left(u^{E}\right)$, excess acoustic impedance $\left(Z^{E}\right)$, excess isentropic compressibility $\left(K_{s}^{E}\right)$ and excess inter molecular free-length $\left(L_{f}^{E}\right)$ were calculated and fitted to the Redlich Kister equation.

Corresponding Author: - K. Vijaya Lakshmi.

Address:- Lecturer in Chemistry, Govt. Degree College (UG \& PG) (Autonomous), Anantapur, A.P., India. 


\section{Material and methods:-}

Methyl acrylate, 2-Alkoxy Ethanols [2-Methoxy Ethanol (2ME), 2-Ethoxy Ethanol (2EE), 2-Butoxy Ethanol (2BE)] of E-Merck make were used in the present investigation. Mixtures were prepared by mixing weighed amounts of the pure liquids adopting the method of closed system by using Mettler balance with the precision of $\pm 0.1 \mathrm{mg}$. Mixtures were allowed to stand for some time before every measurement so as to avoid air bubbles. The purities of the liquids were checked by comparing the values of densities and ultrasonic velocities with literature data and are given in Table 1.

The measurements were made with proper care in an Air Conditioned room to avoid evaporation loss. The densities of liquids and their mixtures were measured using bicapillary pycnometer having a capillary diameter of $0.85 \mathrm{~mm}$, which was calibrated using double distilled water. The necessary buoyancy corrections were applied. The density $(\rho)$ values were reproducible within $\pm 0.2 \mathrm{Kg} \mathrm{m}^{-3}$. The ultrasonic velocity (u) measurements were made by a single frequency $(2 \mathrm{MHz})$ variable path interferometer with an accuracy of $\pm 0.03 \%$. A thermostatically controlled, well stirred constant temperature water bath, Schott Gerrate (Model CT 050/2 made in Germany) whose temperature was controlled to $\pm 0.02 \mathrm{~K}$ was used for all the measurements.

Table 1: Comparison of Experimental densities $(\rho)$ and ultrasonic velocities (u) of pure liquids with literature at $308.15 \mathrm{~K}$

\begin{tabular}{|l|c|c|c|c|}
\hline \multirow{2}{*}{\multicolumn{1}{|c|}{ Liquid }} & \multicolumn{2}{|c|}{$\begin{array}{c}\text { Density }(\boldsymbol{\rho}) \mathbf{x} \mathbf{1 0}^{-3} \\
\mathbf{K g ~ m}^{-3}\end{array}$} & \multicolumn{2}{c|}{$\begin{array}{c}\text { Ultrasonic Velocity (u) } \\
\text { ms }^{-\mathbf{- 1}}\end{array}$} \\
\cline { 2 - 5 } & EXP & LIT & EXP & LIT \\
\hline Methyl Acrylate & 0.9367 & $0.93565[3]$ & 1141.0 & $1140.0[5$ \& 6] \\
\hline 2-methoxy ethanol & 0.9529 & $0.9511[4]$ & 1342.0 & $1318.8(4)$ \\
\hline 2-ethoxy ethanol & 0.9163 & $0.9164[4]$ & 1295.0 & $1272.4(4)$ \\
\hline 2-butoxy ethanol & 0.8887 & $0.8887[4]$ & 1279.0 & $1260.8(4)$ \\
\hline
\end{tabular}

\section{Results and discussions:-}

From the measured density $(\rho)$ and ultrasonic velocity $(u)$ the various acoustical parameters such as $K_{S}, Z, L_{f}$ and $R_{A}$ were calculated using the following equations $1,2,3 \& 4$ respectively and are incorporated in Table 2 for the binary systems under study.

$$
\begin{gathered}
K_{s}=1 / u^{2} \rho \\
Z=\rho u \\
L_{f}=K\left(K_{s}\right)^{1 / 2}
\end{gathered}
$$

Where ' $\mathrm{K}$ ' is Jacobson's constant [7].

$$
R_{A}=\rho / \rho_{o}\left(u_{o} / u\right)^{1 / 3}
$$

The excess functions $\mathrm{Y}^{\mathrm{E}}$ have being calculated using the relation:

$$
Y^{E}=Y_{m i x}-\left(X_{1} Y_{1}+X_{2} Y_{2}\right)
$$

Where $\mathrm{Y}$ denotes u, $Z, K_{S}$ and $L_{f}$ respectively, $\mathrm{X}$ is the mole fraction and suffixes $1 \& 2$ denote the components $1 \&$ 2 in binary mixture and the values are given in Table 3.

The dependence of $u^{E}, Z^{E}, K_{S}{ }^{E}$ and $L_{f}^{E}$ on the mole fraction of methyl acrylate $\left(\mathrm{X}_{\mathrm{MA}}\right)$ for all the three systems was fitted to the following Redlich-Kister equation by the least-squares polynomial method and the values are given in Table 4.

$$
Y^{E}=x(1-X) \sum_{i} A_{i}(2 x-1)^{i}
$$

Where $Y^{E}$ is $u^{E}, Z^{E}, K_{S}^{E}$ and $L_{f}^{E}$ excess parameters.

The parameters $\mathrm{A}_{\mathrm{i}}$, obtained by a linear least squares polynomial fitting procedure, are also given in Table 3 together with the standard deviations $(\sigma)$ values.

From the Table 2, it is clear that the values of $u, Z, K_{s}, L_{f}$ and $R_{A}$ varied with the mole fraction of MA (X $\left.\mathrm{X}_{\mathrm{MA}}\right)$. This indicates the presence of interactions between the components in these binary liquid mixtures. The variations of ultrasonic velocity for the mixtures depend on the values of $\mathrm{L}_{\mathrm{f}}$. It is observed that, decrease in ultrasonic velocity and the corresponding increase in $L_{f}$ with mole fraction of MA (Table 2) for all the systems are in accordance with the view proposed by Eyring and Kincaid [8]. However, the excess functions which are a measure of the deviations 
from the ideal behaviour are relatively more sensitive to the intermolecular interactions between the unlike molecules of the mixture than the pure acoustical parameters as explained above.

The positive deviations in $u^{E}$ and $Z^{E}$ (Figs. 1 to 2) for all the systems of MA and 2-Alkoxy Ethanols are observed over the entire range of composition except 2-methoxy ethanol. These trends for these systems again support the view that, the interactions between unlike molecules are quite possible and these values are in the following order.

$$
\mathrm{MA}+2 \mathrm{BE}>\mathrm{MA}+2 \mathrm{EE}>\mathrm{MA}+2 \mathrm{ME}
$$

In general if the media is dense, the ultrasonic velocity value will be more and if the media is less dense, the ultrasonic velocity value will be less. When two liquids are mixed, if they condense or compress more, the ultrasonic velocity value will be positive [9]. From Fig. 1 it is clear that $u^{E}$ values are positive for all the systems except for 2Methoxy Ethanol. This indicates that the mixtures are compressed more and it is natural to get positive excess ultrasonic velocities. In Fig 2, Excess acoustic impedance $\left(Z^{E}\right)$ with composition of liquid mixtures exhibited positive deviations as per the equation 2. A similar observation was reported by Eswari Bai et al [10], Vijaya lakshmi et al [11] and Sastry et al [12].

From the Figs. $3 \& 4$ that $K_{S}{ }^{E}$ and $L_{f}^{E}$ are negative for all the systems over the whole mole fraction range. In general, $K_{S}{ }^{E}$ and $L_{f}^{E}$ values depend upon three factors.

(i) Mutual disruption of associated present in the pure liquids, defined by Jacobson [7]

(ii) Formation of weak $\mathrm{H}$ - bonding by dipole-induced dipole interaction between unlike molecules and

(iii) Geometrical complex fitting formation between the component molecules [13].

First factor contributes to positive $K_{S}{ }^{E}$ values, whereas the remaining two factors lead to negative $K_{S}{ }^{E}$ values. The resultant values for the present mixtures are due to the net effect of above all the three factors [14].

The negative deviations of $K_{S}^{E}$ and $L_{f}^{E}$ values indicated that the presence of strong interactions between unlike molecules, which may be resulted in complex formation. The polar nature of the two unlike molecules leads to formation of $\mathrm{H}$-bonding between the oxygen atom of $>\mathrm{C}=\mathrm{O}$ group of MA with hydrogen atom of $-\mathrm{OH}$ group of 2Alkoxy Ethanols $[>\mathrm{C}=\mathrm{O} \ldots \ldots . \mathrm{H}-\mathrm{O}]$ and also expected intermolecular $\mathrm{H}$-bonding between 2-Alkoxy Ethanol molecules which may be due to complex formation.

2-Alkoxy Ehanol with the interstitial accommodation of smaller sized MA molecules into interstitial space of bigger size 2-Alkoxy Ethanol molecules. Thus, the complex formation between the two component molecules lead to a decrease in the intermolecular distance thereby decreasing the isentropic compressibilities of the mixtures. The negative values obtained for the $K_{S}^{E}$ and $L_{f}^{E}$ are in the following order:

$$
\mathrm{MA}+2 \mathrm{BE}>\mathrm{MA}+2 \mathrm{EE}>\mathrm{MA}+2 \mathrm{ME}
$$

Further, it is also observed from the experimental results that the negative contributions increase with increase in chain length of 2-Alkoxy ethanols. The change in magnitude of negative values of $K_{S}{ }^{E}$ and $L_{f}^{E}$ from 2-Methoxy Ethanol (2ME), 2-Ethoxy Ethanol (2EE), 2-Butoxy Ethanol (2BE) shows that, increase in chain length of 2-Alkoxy ethanols lead to less compressibility in homologous series. Further the data suggests that the strength of complex formation between unlike molecules increase from 2-Methoxy Ethanol (2ME) to 2-Butoxy Ethanol (2BE). This conclusion is supported by Fort and Moore [15], Mahendranath Roy [16], Douhéreta [17] and Sastry et al [18].

\section{Conclusions:-}

From the above discussion, following conclusions are drawn.

1. The observed variation of the properties of the mixtures studied support the view that the interactions between unlike molecules is predominant and characterised by the positive $\mathrm{u}^{\mathrm{E}}$ and $\mathrm{Z}^{\mathrm{E}}$ for all mixtures except for 2-methoxy ethanol.

2. The Excess isentropic compressibility and Excess Inter molecular free-length values are negative for all the mixtures. The negative contributions increase with increase in chain length of 2-Alkoxy ethanols.

3. The possible intermolecular interactions of hydrogen bonding between unlike molecules of Methyl Acrylate and 2-Alkoxy Ethanols and inter H-bonding between 2-Alkoxy Ethanols molecules which leads to complex formations between the component molecules. 
4. Interstitial accommodation of MA molecules into the 2-Alkoxy Ethanol molecules is due to their differences in size and shape.

Table 2:- Values of density $(\rho)$, ultrasonic velocity $(\mathrm{u})$, acoustic impedance $(\mathrm{Z})$, isentropic compressibility $\left(\mathrm{K}_{S}\right)$, Inter molecular free-length $\left(\mathrm{L}_{\mathrm{f}}\right)$ and relative association $\left(\mathrm{R}_{\mathrm{A}}\right)$ for the binary liquid mixtures of Methyl Acrylate (MA) with 2-Alkoxy Ethanols at 308.15 K.

\begin{tabular}{|c|c|c|c|c|c|c|}
\hline $\begin{array}{c}\text { Mole } \\
\text { fraction of } \\
\text { MA }\left(\mathbf{X}_{\mathrm{MA}}\right)\end{array}$ & $\begin{array}{l}\rho \times 10^{-3} \\
\mathrm{Kg} \mathrm{m}^{-3}\end{array}$ & $\mathbf{m ~ s}^{-1}$ & $\begin{array}{c}\mathrm{Z} \times \mathbf{1 0}^{-4} \\
\mathrm{Kg} \mathrm{m}^{-2} \mathrm{~s}^{-1}\end{array}$ & $\begin{array}{c}\mathrm{K}_{\mathrm{S}} \mathbf{x} \mathbf{1 0}^{11} \\
\mathbf{m}^{2} \mathbf{N}^{-1}\end{array}$ & $\begin{array}{c}\mathbf{L}_{\mathbf{f}} \times \mathbf{1 0}^{12} \\
\mathbf{m}\end{array}$ & $\begin{array}{c}\text { Relative } \\
\text { association } \\
\left(\mathbf{R}_{\mathbf{A}}\right)\end{array}$ \\
\hline \multicolumn{7}{|c|}{ Methyl Acrylate (MA) + 2-Methoxy Ethanol (2ME) } \\
\hline 0.0000 & 0.9529 & 1342.0 & 1.2788 & 58.2704 & 5.0555 & 1.0000 \\
\hline 0.0894 & 0.9513 & 1322.0 & 1.2576 & 60.1490 & 5.1364 & 1.0033 \\
\hline 0.1810 & 0.9497 & 1302.0 & 1.2365 & 62.1169 & 5.2197 & 1.0067 \\
\hline 0.2747 & 0.9480 & 1282.0 & 1.2154 & 64.1796 & 5.3057 & 1.0102 \\
\hline 0.3708 & 0.9464 & 1262.0 & 1.1944 & 66.3433 & 5.3944 & 1.0138 \\
\hline 0.4692 & 0.9448 & 1242.0 & 1.1734 & 68.6147 & 5.4859 & 1.0174 \\
\hline 0.5700 & 0.9432 & 1222.0 & 1.1526 & 71.0008 & 5.5805 & 1.0212 \\
\hline 0.6734 & 0.9416 & 1202.0 & 1.1318 & 73.5094 & 5.6782 & 1.0251 \\
\hline 0.7795 & 0.9399 & 1182.0 & 1.1110 & 76.1491 & 5.7793 & 1.0290 \\
\hline 0.8883 & 0.9383 & 1162.0 & 1.0903 & 78.9290 & 5.8838 & 1.0331 \\
\hline 1.0000 & 0.9367 & 1142.0 & 1.0697 & 81.8592 & 5.9920 & 1.0373 \\
\hline \multicolumn{7}{|c|}{ Methyl Acrylate (MA) + 2-Ethoxy Ethanol (2EE) } \\
\hline 0.0000 & 0.9163 & 1295.0 & 1.1866 & 65.0763 & 5.3426 & 1.0000 \\
\hline 0.1042 & 0.9183 & 1279.7 & 1.1752 & 66.4936 & 5.4005 & 1.0062 \\
\hline 0.2074 & 0.9204 & 1264.4 & 1.1637 & 67.9616 & 5.4598 & 1.0125 \\
\hline 0.3097 & 0.9224 & 1249.1 & 1.1522 & 69.4827 & 5.5205 & 1.0189 \\
\hline 0.4110 & 0.9245 & 1233.8 & 1.1406 & 71.0595 & 5.5828 & 1.0253 \\
\hline 0.5114 & 0.9265 & 1218.5 & 1.1289 & 72.6948 & 5.6467 & 1.0319 \\
\hline 0.6109 & 0.9285 & 1203.2 & 1.1172 & 74.3916 & 5.7122 & 1.0385 \\
\hline 0.7095 & 0.9306 & 1187.9 & 1.1054 & 76.1529 & 5.7794 & 1.0452 \\
\hline 0.8072 & 0.9326 & 1172.6 & 1.0936 & 77.9822 & 5.8484 & 1.0521 \\
\hline 0.9040 & 0.9347 & 1157.3 & 1.0817 & 79.8830 & 5.9193 & 1.0590 \\
\hline 1.0000 & 0.9367 & 1142.0 & 1.0697 & 81.8592 & 5.9920 & 1.0660 \\
\hline \multicolumn{7}{|c|}{ Methyl Acrylate (MA) + 2-Butoxy Ethanol (2BE) } \\
\hline 0.0000 & 0.8887 & 1279.0 & 1.1366 & 68.7866 & 5.4928 & 1.0000 \\
\hline 0.1323 & 0.8935 & 1265.3 & 1.1305 & 69.9066 & 5.5373 & 1.0090 \\
\hline 0.2555 & 0.8983 & 1251.6 & 1.1243 & 71.0636 & 5.5830 & 1.0181 \\
\hline 0.3704 & 0.9031 & 1237.9 & 1.1179 & 72.2592 & 5.6297 & 1.0273 \\
\hline 0.4779 & 0.9079 & 1224.2 & 1.1115 & 73.4949 & 5.6777 & 1.0366 \\
\hline 0.5785 & 0.9127 & 1210.5 & 1.1048 & 74.7726 & 5.7268 & 1.0460 \\
\hline 0.6731 & 0.9175 & 1196.8 & 1.0981 & 76.0941 & 5.7772 & 1.0555 \\
\hline 0.7621 & 0.9223 & 1183.1 & 1.0912 & 77.4613 & 5.8289 & 1.0651 \\
\hline 0.8459 & 0.9271 & 1169.4 & 1.0842 & 78.8764 & 5.8819 & 1.0748 \\
\hline 0.9251 & 0.9319 & 1155.7 & 1.0770 & 80.3416 & 5.9362 & 1.0846 \\
\hline 1.0000 & 0.9367 & 1142.0 & 1.0697 & 81.8592 & 5.9920 & 1.0946 \\
\hline
\end{tabular}


Table 3:- Values of excess ultrasonic velocity $\left(\mathrm{u}^{\mathrm{E}}\right)$, excess acoustic impedance $\left(\mathrm{Z}^{\mathrm{E}}\right)$, excess isentropic compressibility $\left(\mathrm{K}_{\mathrm{S}}^{\mathrm{E}}\right)$ and excess intermolecular free-length $\left(\mathrm{L}_{\mathrm{f}}^{\mathrm{E}}\right)$ for the binary liquid mixtures of Methyl Acrylate (MA) + 2-Alkoxy Ethanols at 308.15 K.

\begin{tabular}{|c|c|c|c|c|}
\hline $\begin{array}{c}\text { Mole } \\
\text { fraction of } \\
\text { MA }\left(\mathrm{X}_{\mathrm{MA}}\right)\end{array}$ & $\begin{array}{c}\mathbf{u}^{\mathrm{E}} \\
\mathbf{m} \mathbf{s}^{-1}\end{array}$ & $\begin{array}{l}\mathrm{Z}^{\mathrm{E}} \times \mathbf{1 0}^{-4} \\
\mathrm{Kg} \mathrm{m}^{-2} \mathrm{~s}^{-1}\end{array}$ & $\begin{array}{c}\mathrm{K}_{\mathrm{S}}{ }^{\mathrm{E}} \times \mathbf{1 0}^{11} \\
\mathbf{m}^{2} \mathrm{~N}^{-1}\end{array}$ & $\begin{array}{c}\mathrm{L}_{\mathrm{f}}^{\mathrm{E}} \times \mathbf{1 0}^{12} \\
\mathrm{~m}\end{array}$ \\
\hline \multicolumn{5}{|c|}{ Methyl Acrylate (MA) + 2-Methoxy Ethanol (2ME) } \\
\hline 0.0000 & 0.0000 & 0.0000 & 0.0000 & 0.0000 \\
\hline 0.0894 & -2.1154 & -0.2503 & -0.2307 & -0.0290 \\
\hline 0.1810 & -3.8054 & -0.4497 & -0.4224 & -0.0529 \\
\hline 0.2747 & -5.0548 & -0.5965 & -0.5712 & -0.0713 \\
\hline 0.3708 & -5.8472 & -0.6890 & -0.6729 & -0.0838 \\
\hline 0.4692 & -6.1660 & -0.7256 & -0.7229 & -0.0898 \\
\hline 0.5700 & -5.9933 & -0.7043 & -0.7160 & -0.0887 \\
\hline 0.6734 & -5.3104 & -0.6232 & -0.6468 & -0.0799 \\
\hline 0.7795 & -4.0978 & -0.4802 & -0.5090 & -0.0627 \\
\hline 0.8883 & -2.3349 & -0.2733 & -0.2959 & -0.0363 \\
\hline 1.0000 & 0.0000 & 0.0000 & 0.0000 & 0.0000 \\
\hline \multicolumn{5}{|c|}{ Methyl Acrylate (MA) + 2-Ethoxy Ethanol (2EE) } \\
\hline 0.0000 & 0.0000 & 0.0000 & 0.0000 & 0.0000 \\
\hline 0.1042 & 0.6416 & 0.0771 & -0.3313 & -0.0980 \\
\hline 0.2074 & 1.1353 & 0.1367 & -0.5958 & -0.1755 \\
\hline 0.3097 & 1.4832 & 0.1789 & -0.7911 & -0.2321 \\
\hline 0.4110 & 1.6873 & 0.2038 & -0.9150 & -0.2673 \\
\hline 0.5114 & 1.7496 & 0.2117 & -0.9648 & -0.2807 \\
\hline 0.6109 & 1.6720 & 0.2027 & -0.9378 & -0.2717 \\
\hline 0.7095 & 1.4563 & 0.1768 & -0.8311 & -0.2397 \\
\hline 0.8072 & 1.1046 & 0.1343 & -0.6415 & -0.1842 \\
\hline 0.9040 & 0.6185 & 0.0753 & -0.3657 & -0.1045 \\
\hline 1.0000 & 0.0000 & 0.0000 & 0.0000 & 0.0000 \\
\hline \multicolumn{5}{|c|}{ Methyl Acrylate (MA) + 2-Butoxy Ethanol (2BE) } \\
\hline 0.0000 & 0.0000 & 0.0000 & 0.0000 & 0.0000 \\
\hline 0.1323 & 4.4308 & 0.2757 & -0.6100 & -0.2153 \\
\hline 0.2555 & 7.6038 & 0.4767 & -1.0630 & -0.3739 \\
\hline 0.3704 & 9.6454 & 0.6094 & -1.3695 & -0.4798 \\
\hline 0.4779 & 10.6657 & 0.6789 & -1.5384 & -0.5369 \\
\hline 0.5785 & 10.7611 & 0.6902 & -1.5771 & -0.5483 \\
\hline 0.6731 & 10.0159 & 0.6472 & -1.4918 & -0.5165 \\
\hline 0.7621 & 8.5049 & 0.5536 & -1.2876 & -0.4440 \\
\hline 0.8459 & 6.2938 & 0.4127 & -0.9688 & -0.3327 \\
\hline 0.9251 & 3.4415 & 0.2273 & -0.5387 & -0.1842 \\
\hline 1.0000 & 0.0000 & 0.0000 & 0.0000 & 0.0000 \\
\hline
\end{tabular}

Table 4:- Parameters of Eq. (6) and Standard deviations

\begin{tabular}{|l|c|c|c|c|c|c|}
\hline Excess Property & $\mathbf{A}_{\mathbf{0}}$ & $\mathbf{A}_{\mathbf{1}}$ & $\mathbf{A}_{\mathbf{2}}$ & $\mathbf{A}_{\mathbf{3}}$ & $\mathbf{A}_{\mathbf{4}}$ & $\boldsymbol{\sigma}$ \\
\hline \multicolumn{7}{|c|}{ Methyl Acrylate (MA) + 2-Methoxy Ethanol (2ME) } \\
\hline $\mathrm{U}^{\mathrm{E}} \mathrm{m} \mathrm{s}^{-1}$ & 0.000194 & -26.2787 & 29.69434 & -3.78305 & 0.36772 & 0.000377 \\
\hline $\mathrm{Z}^{\mathrm{E}} \times 10^{-4} \mathrm{Kg} \mathrm{m}^{-2} \mathrm{~s}^{-1}$ & 0.000017 & -3.11401 & 3.56742 & -0.50819 & 0.05479 & 0.000043 \\
\hline $\mathrm{K}_{\mathrm{S}}^{\mathrm{E}} \times 10^{11} \mathrm{~m}^{2} \mathrm{~N}^{-1}$ & -0.000009 & -2.81752 & 2.64154 & 0.16524 & 0.01075 & 0.000036 \\
\hline $\mathrm{L}_{\mathrm{f}}^{\mathrm{E}} \times 10^{12} \mathrm{~m}$ & 0.000018 & -0.35443 & 0.34199 & 0.01154 & 0.00092 & 0.000026 \\
\hline \multicolumn{7}{|c|}{ Methyl Acrylate (MA) + 2-Ethoxy Ethanol (2EE) } \\
\hline $\mathrm{U}^{\mathrm{E}} \mathrm{m} \mathrm{s}^{-1}$ & 0.000011 & 6.84109 & -6.53079 & -0.30159 & -0.00877 & 0.000078 \\
\hline
\end{tabular}




\begin{tabular}{|l|c|c|c|c|c|c|}
\hline $\mathrm{Z}^{\mathrm{E}} \times 10^{-4} \mathrm{Kg} \mathrm{m}^{-2} \mathrm{~s}^{-1}$ & 0.000001 & 0.82070 & -0.76919 & -0.05043 & -0.00109 & 0.000036 \\
\hline $\mathrm{K}_{\mathrm{S}}^{\mathrm{E}} \times 10^{11} \mathrm{~m}^{2} \mathrm{~N}^{-1}$ & 0.000041 & -3.48037 & 2.82118 & 0.49136 & 0.16777 & 0.000070 \\
\hline $\mathrm{L}_{\mathrm{f}}^{\mathrm{E}} \times 10^{12} \mathrm{~m}$ & 0.0000003 & -1.03289 & 0.87263 & 0.12763 & 0.03263 & 0.000016 \\
\hline \multicolumn{7}{|c|}{ Methyl Acrylate (MA) + 2-Butoxy Ethanol (2BE) } \\
\hline $\mathrm{U}^{\mathrm{E}} \mathrm{m} \mathrm{s}^{-1}$ & 0.000933 & 37.32526 & -28.05933 & -4.9196 & -4.34371 & 0.00228 \\
\hline $\mathrm{Z}^{\mathrm{E}} \times 10^{-4} \mathrm{Kg} \mathrm{m}^{-2} \mathrm{~s}^{-1}$ & -0.000103 & 2.30973 & -1.64395 & -0.25808 & -0.40741 & 0.00025 \\
\hline $\mathrm{K}_{\mathrm{S}}^{\mathrm{E}} \times 10^{11} \mathrm{~m}^{2} \mathrm{~N}^{-1}$ & 0.000510 & -5.10003 & 3.54555 & 0.14277 & 1.41024 & 0.00124 \\
\hline $\mathrm{L}_{\mathrm{f}}^{\mathrm{E}} \times 10^{12} \mathrm{~m}^{-0.000145}$ & -1.80274 & 1.27136 & 0.11476 & 0.41621 & 0.00034 \\
\hline
\end{tabular}

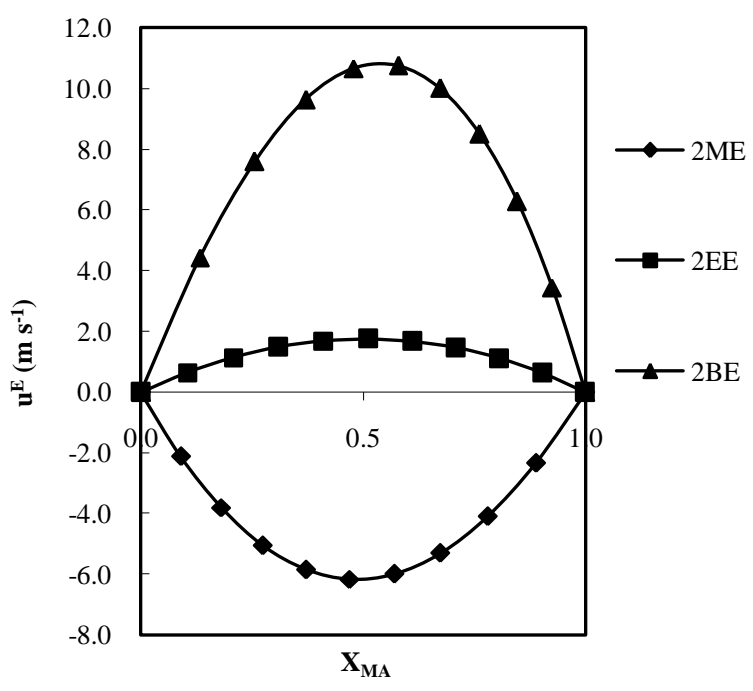

Fig: 1:- Plots of Excess Ultrasonic velocities $\left(\mathrm{u}^{\mathrm{E}}\right)$ vs mole fraction of Methyl Acrylate $\left(\mathrm{X}_{\mathrm{MA}}\right)$ for binary mixtures of Methyl Acrylate $\left(\mathrm{X}_{\mathrm{MA}}\right.$ ) with 2-Methoxy Ethanol (2ME, - -), 2-Ethoxy Ethanol (2EE, - $\left.-\mathbf{-}\right)$, 2-Butoxy Ethanol (2BE, $-\mathbf{\Delta}-)$, at $308.15 \mathrm{~K}$.

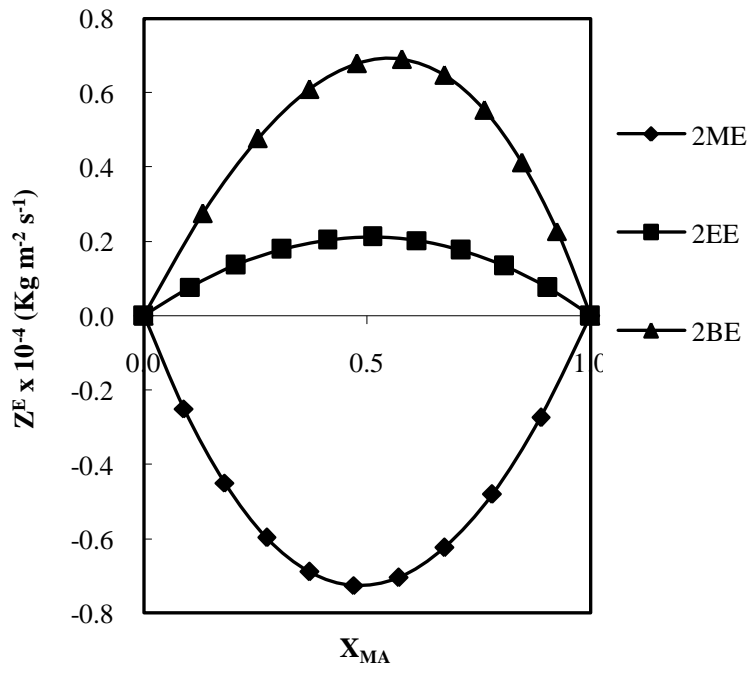

Fig: 2:- Plots of Excess acoustic impedance $\left(\mathrm{Z}^{\mathrm{E}}\right)$ vs mole fraction of Methyl Acrylate $\left(\mathrm{X}_{\mathrm{MA}}\right)$ for binary mixtures of Methyl Acrylate $\left(\mathrm{X}_{\mathrm{MA}}\right)$ with 2-Methoxy Ethanol (2ME, --), 2-Ethoxy Ethanol (2EE, - - -), 2-Butoxy Ethanol $\left(2 \mathrm{BE},-\boldsymbol{\Lambda}^{-}\right)$at $308.15 \mathrm{~K}$. 


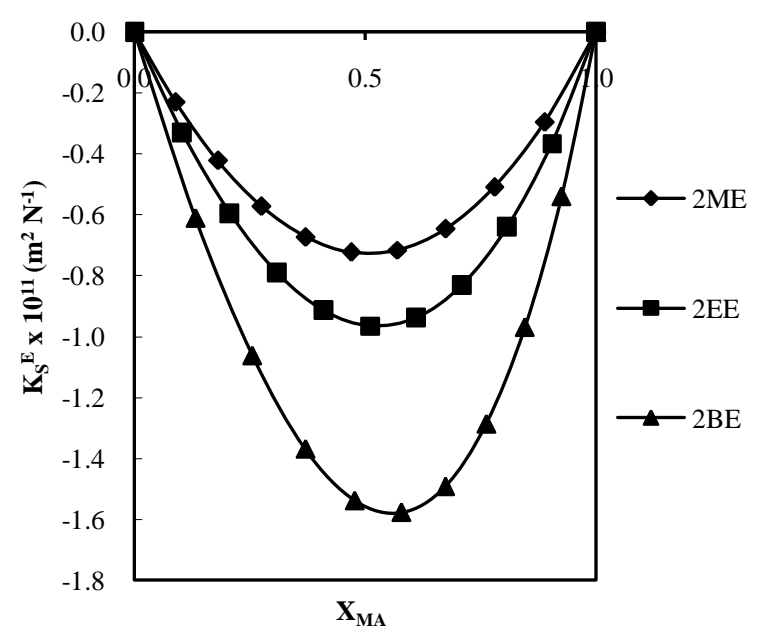

Fig: 3:- Plots of Excess isentropic compressibility $\left(\mathrm{K}_{\mathrm{s}}^{\mathrm{E}}\right)$ vs mole fraction of Methyl Acrylate $\left(\mathrm{X}_{\mathrm{MA}}\right)$ for binary mixtures of Methyl Acrylate $\left(\mathrm{X}_{\mathrm{MA}}\right)$ with 2-Methoxy Ethanol 2ME, - -$)$, 2-Ethoxy Ethanol (2EE, $\left.-\mathbf{\square}^{-}\right)$, 2-Butoxy Ethanol (2BE, $\left.-\mathbf{\Lambda}^{-}\right)$at $308.15 \mathrm{~K}$.

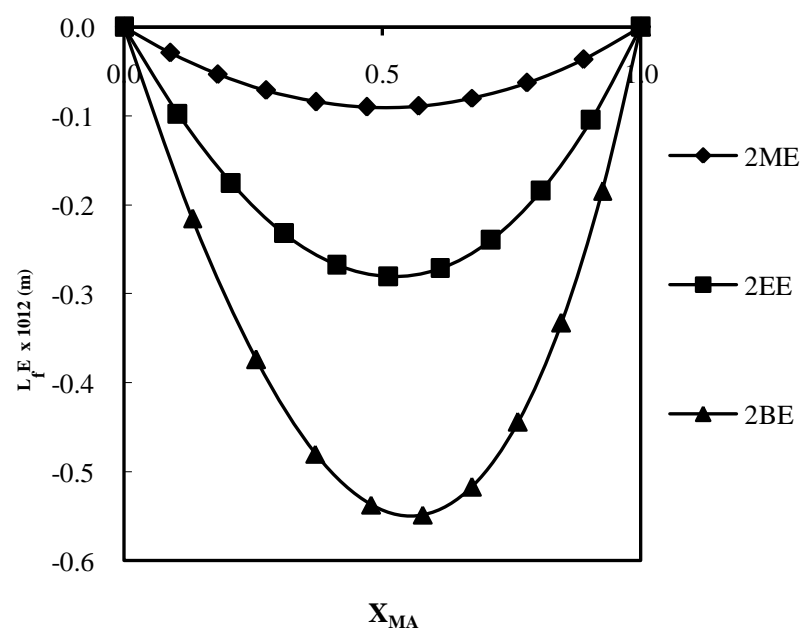

Fig: 4:- Plots of Excess intermolecular free-length $\left(\mathrm{L}_{\mathrm{f}}^{\mathrm{E}}\right)$ vs mole fraction of Methyl Acrylate $\left(\mathrm{X}_{\mathrm{MA}}\right)$ for binary mixtures of Methyl Acrylate $\left(\mathrm{X}_{\mathrm{MA}}\right)$ with 2-Methoxy Ethanol (2ME, - -), 2-Ethoxy Ethanol (2EE, $-\mathbf{-}-)$, 2-Butoxy Ethanol (2BE, $-\mathbf{\Delta}-)$ at $308.15 \mathrm{~K}$.

\section{References:-}

1. H. A. Zarei, H. Ilokhani (2003), "Excess molar enthalpies of formamide + some alkan-1-ols (C1-C6) and their correlations at $298.15 \mathrm{~K}$ ", Thermochim. Acta, 405, 123.

2. H. Ilokhani, H. A. Zarei (2002), "Excesss Molar Enthalpies of N, N-Dimethyl formamide + Alkan-1-ols (C1C6) at 298.15K", J. Chem. Eng. Data, 47, 195.

3. Patil Sujatha, S. and Mirgane Sunil, R. (2012), "Volumetric and viscometric behaviour of acrylic esters with hexane-2-ol at T= (298.15 And 308.15) K", Int. J. of Res. in Chem. and Envir, 2(1), 166.

4. R. Balaji, M. Gowri Sankar, M. Chandra Shekar (2016), "FT-IR Spectroscopic study of excess thermodynamic properties of liquid mixtures containing N-methyl formamide with 2-alkoxyethanols at various temperatures", Journal of Molecular Liquids, 216, 330.

5. N. V. Sastry, M. K. Valand, J. George and S. R. Patel (2002), "Densities, Viscosities, Speed of Sound and Relative Permittivity for Methyl Acrylate +1 - Alcohols (C1- C6) at T=308.15 K and 318.15 K", Journal of Chemical \& Engineering Data, 47, 262. 
6. Sujatha S. Patil and Sunil R. Mirgane (2013), "Thermodynamic study of binary mixtures of methyl acrylate and ethyl acrylate with octane-1-ol", Advances in Applied Science Research, 4(3), 329.

7. Jacobson, B. (1952), "Intermolecular free length in liquid state adiabatic and Isothermal compressibility", Acta Chem. Scand., 6, 1485 and J. Chem. Phys., 20, 927.

8. John F. Kincaid and Henry Eyring (1938), "Free Volumes and Free Angle Ratios of Molecules in Liquids", $J$. Chem. Phys. 6, 620.

9. K. Vijaya Lakshmi (2016), "Study of Thermodynamic and Transport Properties of Binary Liquid Mixtures of Methyl Acrylate with Alkoxy Ethanols at 308.15 K", International Journal of Science and Research, 5 (7) 2082.

10. Eswari Bai, M., Subha, M.C.S. (2004), Narayana Swamy, G. \& Chowdoji Rao, K," Acoustical studies of molecular interactions in binary liquid mixtures of Butoxy ethanol with some amines at $308.15 \mathrm{~K}$ ", J. Pure and appl. ultrasonics, 26, 79.

11. Vijaya Lakshmi, K., Suhasini, D. M., Jayachandra Reddy, N., Ravi Kumar, K., Chowdoji Rao, K. and Subha M. C. S. (2014), "Density and ultrasonic velocity studies on binary mixtures of methyl acrylate with benzenes at 308.15 K", International Journal of Current Research, 6, 5.

12. N. V. Sastry and S. R. Patel (2000), "Densities, viscosities and speed of sound and excess properties of binary mixtures of Methyl methacrylate with alkoxyethanols and 1-alcohols at 298.15 and 308.15 K", International Journal of Thermo physics, 21, 1153.

13. Storey, L.R.O. (1953), "Ultrasonic Absorption in Mixtures of Ethyl Alcohol and Water", Proc. Phys. Soc. (London), 65B, 943.

14. Mahra, R., Pamcholi (2005), M., "Acoustic studies of systems of aliphatic and aromatic hydrocarbons with 1butanol at 298, 308 and 318K and application of theoretical approaches", J. Indian Chem. Soc., 82, 791.

15. Fort, R. J. and Moore, W. R. (1966), "Viscosities of binary liquid mixtures", Trans Faraday Soc., 62, 1112.

16. Mahendranath Roy, Radhey Shyam Sah, Prasanna Pradhan (2010), "Densities, Viscosities Sound Speeds, Refractive Indices and Excess Properties for Binary Liquid Mixtures of Isoamyl alcohol with some Alkoxyethanols", Int. J. ThermoPhys., 31, 316.

17. Gerard Douhéreta, Cynthia Salgado, Michaël I. Davis, Jesus Loya (1992), "Ultrasonic speeds and isentropic functions of 2-(2-alkoxyethoxy)ethanol + water at 298.15 K", Thermochimica Acta, 207, 313.

18. N. V, Sastry and P. Bahadur (2003), "Densities, Speed of Sound, Excess Volumes and Excess Isentropic Compressibilities of Methyl Acrylate + 1-Propanol (or 1-Butanol) + Hydrocarbons (n- Hexane, n- Heptane, Cyclohexane, Benzene and Toluene) at 308.15 K”, International Journal of Thermo physics, 24, 447. 